\title{
Role of endotoxin in the etiology of periapical lesions: molecular mechanisms involved in endotoxin's recognition and cell activation
}

\author{
Papel da endotoxina na etiologia da lesão periapical: mecanismos moleculares envolvidos no seu \\ reconhecimento e na ativação celular
}

\author{
Marília Pacífico LUCISANO ${ }^{1}$ \\ Paulo NELSON-FILHO' \\ Raquel Assed Bezerra da SILVA ${ }^{1}$ \\ Léa Assed Bezerra da SILVA ${ }^{1}$ \\ Andiara DE ROSSI ${ }^{1}$
}

\begin{abstract}
Periapical lesions are diseases resulting from contamination and necrosis of dental pulp and the progression of this infection toward the periapical tissues. Technological advances in microbiological culture and identification have shown that anaerobic microorganisms, especially Gram-negative, are predominate in root canals of teeth with pulp necrosis and chronic periapical lesions. Gram-negative bacteria not only have different factors of virulence and generate products and sub-products that are toxic to apical and periapical tissues, but also contain endotoxin in the outer membrane of their cell wall. This information is important because endotoxin is released during multiplication or bacterial death, causing a series of biological effects that lead to an inflammatory reaction and resorption of mineralized tissues. Thus, the aim of this work is to carry out a review of the literature on the role of bacterial endotoxin in the etiology of periapical lesions, its mechanism of action, and to elucidate molecular mechanisms involved in endotoxin's recognition by the immune system and cell activation.
\end{abstract}

Indexing terms: Anaerobic bacteria. Endotoxins. Periapical tissue.

\section{RESUMO}

As lesões periapicais são patologias resultantes da contaminação e necrose da polpa dental e progressão da infecção em direção aos tecidos periapicais. Os avanços tecnológicos na cultura e identificação microbiana demonstraram que, em canais radiculares de dentes portadores de necrose pulpar e lesão periapical crônica, predominam os microrganismos anaeróbios, particularmente os Gram-negativos. As bactérias Gram-negativas, além de possuírem diferentes fatores de virulência e gerarem produtos e subprodutos tóxicos aos tecidos apicais e periapicais, contêm a endotoxina em sua parede celular. Esse conhecimento é importante, uma vez que a endotoxina é liberada durante a multiplicação ou morte bacteriana, exercendo uma série de efeitos biológicos relevantes, que conduzem a uma reação inflamatória e à reabsorção dos tecidos mineralizados. Sendo assim, o objetivo deste trabalho foi efetuar uma revisão da literatura relativa ao papel da endotoxina bacteriana na etiologia das lesões periapicais, seu mecanismo de ação, bem como elucidar mecanismos moleculares envolvidos no seu reconhecimento pelo sistema imunológico e na ativação celular.

Termos de indexação: Bactérias anaeróbias. Endotoxinas. Tecido periapical.

\section{INTRODUCTION}

Characteristics of a tooth with a chronic periapical lesion include a long infectious process, as well as an imbalance between the number and virulence of microorganisms present on root canal system with regard to the resistance of the host ${ }^{1-2}$.

Since 1980, with technological advancements in methods of cultivation and identification of microorganisms, the concept of endodontic infection was revolutionized by the use of methods of microbiological culture in anaerobic conditions. This made it possible to identify the predominant microbiota in cases of teeth with and without chronic periapical reactions ${ }^{2-3}$.
It is currently known that the infection in deciduous and permanent teeth with pulp necrosis and chronic periapical lesion is polymicrobial, with a predominance of strict anaerobic microorganisms, particularly Gram-negative ${ }^{1,3-5}$.

In dentistry, many studies using different methodologies in vivo and in vitro have emphasized the importance of Gram-negative anaerobic bacteria and endotoxin in the etiology of chronic periapical lesions..$^{3,6-7}$

The Bacterial Endotoxin (LPS) has been widely studied. ${ }^{3,8-9}$ In fact, there is a great interest in the understanding of its structure and its mechanism of action, particularly of the molecular pathways involved in its recognition and cellular signaling, ${ }^{10-15}$ as well as the forms of its inactivation 3,16 .

\footnotetext{
${ }^{1}$ Universidade de São Paulo, Faculdade de Odontologia, Departamento de Clínica Infantil, Odontologia Preventiva e Social. Av. do Café, s/n., Monte Alegre, 14040-904, Ribeirão Preto, SP, Brasil. Correspondência para / Correspondence to: P NELSON FILHO. E-mail: <nelson@forp.usp.br>.
} 
Therefore, the objective of this study is to carry out a review of the literature on the role of bacterial endotoxin in the etiology of periapical lesions, as well as to elucidate molecular mechanisms involved in its recognition by the immune system and in cell activation.

\section{Etiology of periapical lesions and the role of endotoxin in located inflammatory response}

Periapical lesions are pathologies resulting from microbial contamination, necrosis of the pulp tissue, and infection progression toward the periodontal ligament and alveolar bone. This pathological condition represents a local immunoinflammatory response due to an increase in the number of microorganisms and their dissemination from the contaminated root canals towards apical and periapical tissues. This results in resorption of the bone and dental tissues ${ }^{17}$.

In the presence of necrotic pulp tissue, the blood supply is compromised. After the development of aerobic and facultative anaerobic bacteria, a polymicrobial infection sets inside the root canal, where, with time, the Gramnegative and anaerobic species predominate ${ }^{1,3}$.

These microbiological changes, characterized by a microbial shift, occur due to factors such as the availability of nutrients, low oxygen tension, and bacterial interactions, which are important ecological determinants. The disintegration of pulp tissue and the tissue fluids - which are essential sources of nutrients are also important factors in these changes ${ }^{18}$.

In deciduous and permanent teeth, this polymicrobial infection is not only located in the main canal, but is widespread in the entire root canal system, including dentinal tubules, apical craters, cemental lacunae, and apical biofilm ${ }^{1,5}$.

The knowledge and understanding of the mechanisms by which bacterial components induce and perpetuate the tissue destruction in inflammatory diseases, such as periapical lesions, is of great importance. Basically, at the site of inflammation and tissue destruction, cells communicate with each other through the interaction of cytokines and other related molecules. The complex cascade of events associated with the tissue destruction and repair mediated by inflammatory response is still a subject of great interest and has been the focus of many research studies. ${ }^{12,19}$

Gram-negative microorganisms, in addition to having different virulence factors and generating products and by-products toxic to the periapical tissues, contain endotoxin in their cell wall $13,20-22$. This knowledge is particularly important, as the endotoxin is released during the multiplication and lysis/death of bacteria, exercing a number of important biological effects that lead to an inflammatory reaction and bone resorption ${ }^{1-2}$.

The endotoxin, present in all Gram-negative bacteria, is composed of polysaccharides (polymerized sugars), lipids (complexes containing fatty acids), and proteins. Structurally, it consists of three distinct regions: "O" side chain, the region of the "core," and lipid A. Endotoxin can also be called lipopolysaccharide (LPS), emphasizing its chemical structure ${ }^{20}$.

LPS can be considered one of the most potent microbial initiators ${ }^{23}$. The toxicity of endotoxin is situated in the region of the molecule corresponding to the lipid component, called lipid A, which is responsible for its biological effects. ${ }^{24-25}$

In addition to studies on the chemical structure of LPS, much has been studied on its mechanism of action. When free to act, the molecules of endotoxin do not cause cell or tissue injuries directly, but stimulate competent cells to release biochemical mediators. Studies have demonstrated that macrophages are the main means of activation of LPS $^{3}$. According to Leonardo et al. ${ }^{16}$, the effects of endotoxin depends on the response of the host, whose oppressive, uncontrolled, and destructive behavior is what makes it biologically harmful.

Even though the bacterial etiology of periapical lesions is widely studied, it is of fundamental importance to establish and to elucidate the effects of LPS on the apical and periapical tissues.

The periapical inflammatory reaction is composed of a mixed inflammatory infiltrate characterized by the presence of neutrophils, T and B lymphocytes, plasmocytes, and macrophages, with higher or lower prevalence of certain cell types depending on the stage of the disease. The neutrophils are present in the initial phase of the development of the periapical lesion, playing an important role in the pathogenesis of the disease. With the timedependent progression of the lesion, the inflammatory process becomes chronic and initiates the recruitment of mononucleated inflammatory cells. Macrophages are the main inflammatory cell type characteristic of this stage. ${ }^{17}$

The molecules of endotoxin of alive, dead, intact, or fragmented bacteria act in macrophages, neutrophils, and fibroblasts, leading to the release of a large number of inflammatory cytokines or bioactive chemical mediators, such as Tumor Necrosis Factor (TNF), Interleukin-1 (IL-1), IL-5, IL-6, IL-8, Interferon-alpha (IF- $\alpha$ ), and prostaglandins ${ }^{1,26-27}$. The IL-1 and TNF- $\alpha$ are among the most potent mediators of bone 
reabsorption. ${ }^{28}$ It has been demonstrated that LPS also induces the expression of the adhesion molecules of leukocytes in endothelial cells and stimulates osteoclast differentiation and bone resorption, particularly through interactions with the receptor TLR-4 in cells of osteoblastic lineage ${ }^{3}$.

Furthermore, LPS is cytotoxic and acts as a potent stimulator of nitric oxide (NO) production ${ }^{23}$. NO is a mediator in the form of gas, produced by the action of the enzyme NO synthase, which is released by neutrophils and macrophages in the inflammatory area and affects the destruction of microorganisms ${ }^{29}$.

LPS also activates Hageman's factor (factor XII of the coagulation cascade) $)^{3}$. Its passage through interendothelial fenestrations during inflammation puts it in immediate contact with the proteins of the basal membrane and tissue, or with the own aggressor agent and/or its products, subjecting them to activation and, as a consequence, making them act on other exudated plasma proteins. The Hageman's factor plays an essential role in the maintenance of vascular and exudative phenomena ${ }^{29}$.

In addition, LPS (lipid $\mathrm{A}$ ) activates the complement system, a set of plasma proteins that are inactive in the blood as part of the plasma in situations of normality. Activating them means changing the configuration of the proteins' molecules or cliave, giving them enzyme capacity. When the complement proteins, in the exudate, or even in the plasma, interact with antigen-antibody complex, they undergo activation and act, on site, as enzymes, opening orifices in the wall of bacteria or foreign cells. Through these orifices, there will be an influx of $\mathrm{Na++}$ and $\mathrm{H}_{2} \mathrm{O}$, elevating the inside osmotic pressure and, finally, leading to bacterial lysis. Subsequently, interaction of these bacteriolysis fragments and other antigens with complement proteins - a phenomenon known as opsonization - occurs, which shortens or eliminates the initial phase of recognition or phagocytosis, optimizing and increasing its efficacy ${ }^{29}$.

In an inflamed area, such as the periapical region, the cell stress is constant in the site's own cells and in inflammatory cells. In this condition, there is an increase in the permeability to calcium with greater inflow to the interior of the cell, activating metabolic pathways ${ }^{29}$. Among these pathways, the action of the cytosolic enzyme phospholipase $A_{2}$ acts on the phospholipids constituents of the plasma membrane by fragmenting them and releasing the molecules of arachidonic acid into the cytosol. These molecules can be subjected to the action of the cyclooxygenase and lipoxygenase pathway, resulting in the synthesis and secretion of prostaglandins and leukotrienes ${ }^{29}$.
In more detail, the metabolism cycle of the arachidonic acid can be explained as follows: phospholipase $A_{2}$ is present in the cell membrane and remains inhibited through annexins (annexin 1). When an inflammatory stimulus reaches the cell, whose intensity overcomes the inhibitory strength of annexin, phospholipase $A_{2}$ acts by degrading the phospholipids of the cell membrane. The products of degradation are the PAF, or platelet activating factor, and arachidonic acid which is very unstable. Arachidonic acid is metabolized by two pathways, which result in the synthesis of 3 families of derivatives. In the lipoxygenases pathway, the hydroxiacids (HPETE), leukotrienes, and lipoxins are synthesized. Through the cyclooxygenases, prostaglandins, prostacyclin and thromboxanes, are released ${ }^{29}$.

In addition to all of these effects, the LPS is mitogenic for B lymphocytes, which causes degranulation of mast cells and activates macrophages, which also will release a series of chemical mediators ${ }^{30}$.

In infected root canals, the endotoxin may contribute to an increase in the release of vasoactive neurotransmitters in the region of nerve endings in periapical tissues, causing pain ${ }^{4}$. In the tissue injury, the non-myelinated nerve endings of the injured area release neuropeptides, which are mediators resulting from a neuronal response to the aggression. This probably occurs simultaneously to the degranulation of mast cells due to the release of free proteins and tissue enzymes. These neuropeptides act as chemical mediators on the endothelial cells, causing vasodilation and increased vascular permeability. In addition, these molecules influence the synthesis and secretion of cytokines and the amplification of other mediators of inflammation ${ }^{29}$.

In addition to causing an inflammatory reaction, the LPS attaches irreversibly to the mineralized tissues, acting as a potent stimulator of bone resorption. This stimulates the synthesis and release of cytokines that activate osteoclasts, such as IL-1 and TNF, as previously described, and also stimulates the release of prostaglandin E2, which also has an influence on these cells ${ }^{8,31}$.

\section{MOLECULAR MECHANISMS INVOLVED IN THE RECOGNITION OF ENDOTOXIN}

\section{Role of LPS binding protein (LBP) and the CD14 receptor in cell activation dependent on LPS}

The innate immune response is the first line of defense against microbial pathogens. The main challenges to the immune system are: recognizing the 
pathogen, organizinge a defense response immediately, and activating adaptive immune responses ${ }^{12-13}$.

A wide variety of bacterial components are able to stimulate the innate immune system. Examples of such components are LPS, peptidoglycan, lipoteichoic acid, lipopeptides, and bacterial DNA. There are various receiving molecules involved in the recognition of these components, which are known as PAMPs or "pathogenassociated molecular patterns." In addition, there are also receptors that recognize endogenous structures and proteins released during inflammation, known as DAMPs or "damage-associated molecular patterns" 27.

As already reported, LPS is a component of the cell wall of Gram-negative bacteria and presents potent immunostimulating activity. It is considered the main mediator of the pathophysiology of septic shock. The mechanisms involved in its recognition are extremely complex and are not completely elucidated ${ }^{13}$.

The current knowledge of the innate immune recognition of bacterial endotoxin is based on the initial discovery that LPS binds to the lipopolysaccharide binding protein, or LBP. The LBP is a serum glycoprotein $(60 \mathrm{kDa})$ produced by hepatocytes of the liver and is considered an acute-phase protein due to its concentration increase after the inflammatory stimulus. The LBP catalyzes the LPS transfer from the bacterial cell wall to the CD14 membrane receptor (CD14m), or soluble receptor CD14 in plasma (CD14s), causing further responses to LPS ${ }^{13,26}$.

CD14 is characterized as a receptor for the bacterial endotoxin and can be considered as the first described pattern recognition receptor. CD14 is a glycoprotein (55kDa) with 356 amino acids and isencoded on chromosome 5 q2331. A single specie of mRNA is translated and processed in the endoplasmic reticulum, where an anchoring protein, the glycosylphosphatidylinositol (GPI), is attached. In the Golgi complex, CD14 is targeted on glycolipid domains and transported to the plasma membrane ${ }^{32}$.

CD14s may result from the secretion of the protein before docking the GPI or from the proteolytic cleavage in the cell membrane. CD14s is present in the circulatory system and in other body fluids. Its levels increase during inflammation and infection ${ }^{27}$.

It has been demonstrated that having a defect in a gene involved in the biosynthesis of anchoring protein GPI causes CD14m to not be expressed in monocytes. In addition, there is an increase in the levels of CD14s, indicating that, in this situation, the majority of CD14s is derived directly from an intracellular too ${ }^{32}$.
The CD14 is expressed predominantly on the surface of myeloid cells, such as monocytes, macrophages, and neutrophils, but also at lower levels in epithelial cells, endothelial cells, and fibroblasts. These cells are also responsive to LPS, since CD14s is also capable of mediating the cell activation ${ }^{27}$.

Although CD14 is identified as a receptor, it is a protein anchored in the GPI and therefore does not possess transmembrane and intracelular domains. The mechanisms by which CD14 transmits cytoplasmic signals are complex and well studied ${ }^{3,14,33}$. Currently, there are still gaps in relation to the events that occur in the cell membrane after binding of LPS 34 .

According to Tobias and Ulevitch (1994) ${ }^{14}$, there may be two types of signaling pathways. In a template, the end GPI interacts with other components of the membrane that transmits the signal, while in the second mechanism, the protein portion of CD14 interacts with another component for signaling. The most probable mechanism for the signal transmission of LPS consists of the connection of this molecule with the receptor CD14m, which stimulates the interaction of a portion of CD14 with a second component of the membrane.

It has been shown that mice with deletion of the gene that encodes the molecule CD14 were hyporesponsive to LPS and showed resistance to lethal effects of this bacterial component, suggesting that the CD14 performs functions that are essential in the recognition and binding of LPS. However, these animals were still able to respond to high concentrations of these molecules ${ }^{35}$. In addition, according to Moreno et al. ${ }^{36}$, the reduction of the CD14m expression in monocytes made these cells unresponsive to the stimulus caused by LPS, as determined by the production of TNF- $\alpha$.

The molecular mechanisms of activation and desensitization of macrophages induced by LPS have been extensively investigated ${ }^{11,13,15}$. It is currently known that CD14 plays a key role in the induction and in the amplification of responses to LPS ${ }^{17}$. According to Wright et al. ${ }^{37}$, CD14 is the primary cellular receptor for the LPS-LBP complex and is directly involved in the regulation of immune responses and in the transmission of signals. LPS, via CD14, activates monocytes and macrophages, causing the release of inflammatory cytokines, such as TNF- $\alpha$, IL-1, IL-6, IL-8 and IL-12. These cytokines trigger the systemic response to acute phase inflammation, including fever, neutrophilia, alterations in lipid metabolism, increased gluconeogenesis, activation of the complement system and the coagulation 
pathway, and hormonal changes, in addition to inducing the synthesis of acute phase proteins. The majority of these proteins are synthesized in hepatocytes and represent the main changes in the plasma protein composition during the acute response, playing an important protective function in host defense during bacterial infection ${ }^{26}$.

In response to LPS, macrophages also secrete a wide variety of other biological mediators, including the platelet activating factor, prostaglandins, enzymes, and free radicals, such as the $\mathrm{NO}^{23}$. The production of inflammatory cytokines and chemical mediators contributes to an efficient control of the growth and spread of invading pathogens. However, the excessive and uncontrolled production of these bioactive substances can lead to serious systemic complications, such as the microcirculatory dysfunction, tissue damage, and septic shock ${ }^{34}$.

The macrophages, in addition to producing classic inflammatory cytokines immediately after contact with LPS, also produce other cytokines after the stimulus, such as IL-8 and macrophage migration inhibitory factor (MIF), which amplify the initial signal and are responsible for orchestrating a complex network of secondary responses. MIF-deficient mice were hyporesponsive to LPS and to Gram-negative bacteria, and also showed resistance to septic shock. Additionally, it has been demonstrated that MIF-deficient macrophages exhibited a significant reduction in the activation of Nuclear Factor- $\kappa B$ (NF- $\kappa B$ ) and in the production of TNF- $\alpha^{30}$.

In summary, the initial phase of recognition of endotoxin by the innate immune system comprises of the binding of LPS to LBP, which catalyzes the transfer of LPS to CD14. This receptor plays an important role in cellular signaling through the potentialization of adhesion and leukocyte activation, including primary functions, such as the phagocytosis and the production of inflammatory cytokines mediated by LPS ${ }^{30}$.

In vivo studies with respect to the function of CD14 become difficult due to the presence of accessory molecules and the important and varied roles that they can perform ${ }^{32}$.

Since CD14 constitutes an anchored protein to the GPI, it has no transmembrane domain and is not able to start the transmission of an intracellular signal. Several studies have demonstrated the existence of additional receptors that act in conjunction with the LPS-CD14 complex to start the process of signaling, which leads to cell activation. This theory was reinforced by means of proving that monoclonal antibodies that block the CD14 could only partially inhibit the binding of LPS, suggesting the participation of other alternative molecules in signal transmission ${ }^{34}$.

These data suggest that the main function of CD14 is to catalyze the transfer of LPS from the extracellular environment to the plasma membrane, which is associated with a complex of receptors ${ }^{34}$.

Obtaining new knowledge on this process has been directed to the identification of molecules belonging to the receptor complex, which plays essential roles in sensitization, binding, and triggering responses to LPS ${ }^{30}$.

\section{Role of Toll-Like Receptor (TLR4) in the receptor complex of LPS}

The Toll-Like Receptors (TLRs) are members of a family of pattern recognition receptors, which recognize molecular structures of pathogenic microorganisms (PAMPs), as well as the endogenous structures and proteins released during the inflammatory response (DAMPs) ${ }^{27}$.

The TLRs, type I transmembrane receptors, are named so because of their genetic similarity with the Toll protein described in drosophila (Drosophila melanogaster), which is essential for the dorso-ventral development and defense of these animals ${ }^{38}$.

These receptors trigger inflammatory responses, activate innate imune responses, and initiate adaptive immune responses to eradicate invading microorganisms ${ }^{23}$. In addition, the recognition of PAMPs by TLRs leads to the induction of adhesion molecules, cytokines, and chemokines, which will regulate the immune inflammatory cell recruitment ${ }^{39}$.

In humans, 10 different TLRs were identified and can be classified according to the types of ligands they recognize. TLR4 is the member of the TLR family characterized as the receptor of bacterial LPS ${ }^{38}$. These receptors are highly expressed in multiple cell types associated with infections of endodontic origin, such as monocytes/macrophages, granulocytes, pulpal fibroblasts, precursors of osteoclasts, and mesenchymal cells ${ }^{40}$.

The TLRs, unlike CD14, represent a type I transmembrane protein, characterized by an extracellular domain (extracellular $\mathrm{N}$-terminal domain), formed by a leucine-rich chain (LRR domain), and an intracellular domain (intracellular C-terminal domain) similar to the receptor for IL-1 (IL-1R), called Toll/receptor IL-1 (TIR). The extracellular domain is related to the recognition of the microorganism, signal transduction, and dimerization of the receptor, while the intracellular domain presents the function to mediate protein-protein interactions between the TLRs and the signal transduction components ${ }^{41}$. 
According to Hoshino et al. ${ }^{42}$, knockout mice for TLR4 are hyporesponsive to LPS, confirming the essential role of this receptor.

The intracellular signaling pathways activated by TRLs have much in common with the signaling of IL-1 receptor (IL-1R) due to their "TIR" domains, (homology to Toll/IL-1R). The activation of signaling through TIR domains results in recruitment of cytoplasmic adaptor molecule MyD88 (which also features a TIR domain) in the activation of kinases of IRAK family and, finally, in the degradation of $\mathrm{I}_{\kappa}-\mathrm{B}$ and in the nuclear translocation of NF- $\mathrm{K}^{38}$.

In addition to an increase in the production of important inflammatory mediators, such as TNF- $\alpha$ and IL-12, the activation of TLRs also results in triggering mechanisms leading to microbial death. Some of these mechanisms may lead to the production of nitrogen reactive species, the induction of inducible nitric oxide synthase (iNOS), and the production of $\mathrm{NO}^{38}$.

Another signaling pathway of TLR4 has been revealed by the observation that certain responses induced by LPS do not require the MyD88 molecule. This MyD88-independent signaling of the TLR4 was identified since the activation of NF$\kappa B$ was decreased, but not absent, in MyD88-deficient cells, while it was completely inhibited in TLR4-deficient cells ${ }^{43}$.

According to Jiang et al. (2000) ${ }^{41}$, there is a physical association of CD14 and TLR4 dependent on LPS. However, the authors did not discern if the binding of LPS triggers a lateral association of these receptors in the plasma membrane or if it occurs during the release of the pre-associated CD14 and TLR4 by an intracellular tool near the membrane.

Later, this group of researchers found that the physical approximation between CD14 and TLR4 is induced in the plasma membrane and therefore, there is no pre-association of these molecules in the cytoplasmic environment. In addition, it was demonstrated that the physical approximation between CD14 and TLR4 precedes the nuclear translocation of NF-KB and that TLR4 requires CD14 to participate in the process of signaling induced by LPS ${ }^{41}$.

Although it is currently accepted that the TLR4 is necessary for the signal transmission in response to LPS, some questions have not yet been clarified. How does TLR4 interact with the CD14-LPS complex to transmit the signal? What are the steps involved? Are TLR4 and CD14 exclusively responsible for the binding of LPS and for signal transmission? In the absence of evidence, we cannot say that the LPS is a ligand for TLR4. The challenge includes not only the identification of the receptor, but also the determination of the exact mechanism of the involvement of this molecule, meaning, how it behaves in an extremely dynamic pathogenic universe ${ }^{34}$.

According to Moreno et al. ${ }^{36}$, the interaction with the ligand LPS is able to induce changes in the expression of the receptor TLR4 or, could even lead to its internalization, since the recognition of LPS at the intracellular level is evident, which is internalized by Golgi Complex.

Based on this statement, this group of researchers has proposed to analyze the relationship between some of the components of the receptor of LPS in human monocytes. After inducing the reduction of the expression of CD14m in monocytes, by means of the treatment of these cells with Brefeldin A (BFA) $(10 \mu \mathrm{g} / \mathrm{ml})$, the authors evaluated the behavior of the TLR4 expression, as well as the effects of LPS in these cells. First, it was proven that, due to the absence of CD14m in monocytes, they behaved as non-responsive to LPS stimulation, measured through the production of TNF- $\alpha$. Then, the authors observed that these cells devoid of CD14 did not show alterations in the TLR4 expression in the presence of LPS. However, when the cultures were preformed in the presence of human serum, LPS induced a change in the TLR4 expression observed in control cells. Furthermore, when anti-CD14 monoclonal antibodies were present in the culture, the effect of the serum was blocked, suggesting an important role for the CD14s in this phenomenon. Finally, it was demonstrated that, although the direct interaction of LPS with TLR4 cannot be ruled out, CD14 is necessary for changes in TLR4 expression induced by LPS ${ }^{36}$.

Currently, there is a consensus that the TLR4 is essential for the signaling of LPS. However, the involvement of other molecules is needed, since the in vitro transfer of TLR4 DNA in cell lines did not confer responsiveness to LPS. This phenomenon was subsequently explained by the identification of another molecule of recognition of LPS, MD- $2^{11}$.

\section{Role of myeloid differentiation protein-2 (MD-2) in the receptor complex of LPS}

The human myeloid differentiation protein-2 (MD2) consists of amino acids with a molecular mass of approximately $18 \mathrm{kDa}$ and has two $\mathrm{N}$-glycosylation sites. ${ }^{30}$ Although MD-2 does not have a transmembrane domain, this protein remains associated with the cell through its interaction with the extracellular end of TLR4 ${ }^{30,38}$.

CD14 is physically associated with a complex that includes TLR4 and MD-2 accessory protein. Each one of these components is essential for efficient signaling induced by LPS ${ }^{38}$. 
According to Shimazu et al., ${ }^{44}$ TLR4 requires an additional molecule, MD-2 - which forms a complex with its extracellular domain - for the effective recognition of LPS and, even for improving the responsiveness to this component.

MD-2 deficient mice did not respond to LPS and survived after experimentally induced septic shock, emphasizing the involvement of MD-2 in responses to this component ${ }^{11}$.

Since MD-2 expression confers responsiveness in cells that had only TLR4, it has been proved that MD-2 is another component of the receptor complex that displays essential participation for the induction of TLR4dependent responses to LPS 45 .

Some groups have proposed that the recognition of LPS by TLR4-MD-2 involves a direct binding, while others suggest that LPS binds to MD-2 and this complex stimulates TLR4 ${ }^{36}$.

MD-2 also plays a regulatory activity in the intracellular distribution of TLR4. In MD-2 deficient cells, TLR4 is not correctly transported to the cell surface, accumulating mainly in the Golgi Complex. In this situation, the recognition and signaling of LPS did not occur. Thus, in macrophages, the contact of TLR4-MD-2 with LPS occurs, most likely, on the cell surface. This indicates that the distribution of TLR4 in the membrane, dependent on the MD-2, is important for the responses to LPS ${ }^{30,45}$.

According to Fujihara et al. ${ }^{30}$, the functionality of the receptor of LPS depends on the expression of at least 3 molecules on the cell surface: CD14, MD-2 and TLR4. The authors also found that glycosylations of both MD-2 and TLR4 are important for the maintenance of the functional integrity of the receptor complex with CD14.

The LPS needs to interact with the TLR4-MD-2 complex to trigger the signaling and this interaction is dependent on CD14m. It should be emphasized that CD14m is not required for the interaction of LPS directly with $M D-2$, suggesting that MD-2 should be a distinct pathway of the TLR4-MD-2 complex, since the latter requires the involvement of CD14m for the interaction with LPS ${ }^{11}$.

As demonstrated by Akashi et al., in 200346, LPS attached to CD14 forms a complex on the cell surface that includes the TLR4 and the MD-2 molecule and initiates one or more intracellular pathways that lead to the expression of inflammatory mediators.

Macrophages derived from the bone marrow of MD-2-deficient mice did not respond to LPS through the production of inflammatory cytokines, confirming that
MD-2 presents a relatively high affinity for LPS. Thus, it is suggested that both TLR4 and MD-2 are important for the binding specificity ${ }^{30}$.

In summary, the evidence indicates that CD14, together with LBP, plays a key role in binding LPS to the TLR4-MD-2 complex. This, in turn, is also directly involved in the triggering of cellular responses.

\section{Other molecules involved}

Initial studies, using a biophysical method to determine the lateral mobility of molecules in lipid bilayer, revealed that LPS binds initially to CD14, and then is transferred to a stable receptor or to a group of receptors. ${ }^{33}$

The same group of researchers later identified a heterogeneous structural complex of four receptors that could interact with LPS. This heterogeneous complex of receptors is composed of heat shock proteins (Hsp) 70 and 90, the receptor for chemokine (CXCR4), and growth and differentiation factor 5 (GDF5) ${ }^{33}$.

By means of other biophysical methods used to determine molecular interactions, it has been demonstrated that LPS, is in fact associated with Hsp70, Hsp90, CXCR4 and GDF5, and that these four molecules form a complex after LPS binding. Incubation with antibodies against any one of the four receptors identified before stimulation with LPS, inhibited the secretion of TNF- $\alpha$. This effect is probably due to interference with other components of the receptor complex ${ }^{34}$

Although TLR4 has never been studied separately as a receptor for LPS in the biochemical experiments of these authors, preliminary data suggest that TLR4 is associated with this complex of receptors and that it is necessary in order to achieve a maximal response ${ }^{34}$.

The potential for combinational diversity, with the purpose of recognizing a wide variety of microbial stimuli, becomes greater when the possibility of interaction of different TLRs receptors in the complex of activation is considered ${ }^{34}$.

Evidence indicates that the responses different pathogens vary depending on the cell type, the composition of molecular complexes of activation, and the intracellular adapter molecules. In addition, it is possible that not only do different cell types use different ways for recognition of LPS, but that the composition of the complexes of activation may change according to the state of cell activation ${ }^{47}$.

Based on findings of Triantafilou \& Triantafilou ${ }^{34}$, a model by which the LPS first binds to CD14 has been proposed. After this interaction, different signaling molecules are recruited to the site of binding, where LPS 
is released gradually toward the lipid bi-layer. There it interacts with the complex of receptors that include Hsp70, Hsp90, CXCR4, GDF5, and TLR4.

This model is in agreement with the data that suggest that the cell activation by LPS occurs in the plasma membrane by lateral diffusion of LPS molecules to the transmebrane proteins, which initiate signaling by cellular stress ${ }^{48}$.

Since CD14 is found in micro-domains, it is possible that the complete system for the recognition of the pathogen is based on the attachment of CD14 by bacterial products and the formation of a signaling complex in the binding site of CD14-LPS in the membrane micro-domains ${ }^{34}$.

According to Triantafilou \& Triantafilou ${ }^{34}$, the innate recognition of bacteria involves the dynamic association of multiple receptors within one or more micro-domains. In addition, the transitory association of different receptors in the activation complex can improve the recognition and/or the distinguishing of different ligands.

Thus, the existence of a group of receptors explains the variety of cascades or signaling events that are stimulated by LPS. Given the great diversity of receptors in these groups of activation, there is a high potential for different combinations of these molecules and for the recognition of a wide range of microbial stimuli34.

Only by expanding our knowledge it is possible to better understand the innate recognition of pathogens and try to direct therapeutic approaches, not only by means of a single pathway of receptors, but through the complex network of molecules that play an essential role in the induction and maintenance of immunoinflammatory responses triggered by LPS ${ }^{34}$.

\section{Other applications in Dentistry}

Becerik etal. ${ }^{39}$ conductedastudy from the knowledge that the initiation and the progression of periodontal disease occur as a result of the immune inflammatory response of the host to oral pathogens, predominantly Gramnegative anaerobic bacteria that colonize the subgingival microenvironment, and that the greater part of the tissue damage that characterizes periodontal disease is indirectly caused by the host's response to infection and, in a smaller proportion, by infectious agents in a direct manner. This study evaluated and compared the levels of expression of TLR4 and CD14m in the gingival tissues of patients with different degrees of periodontal disease, emphasizing the important role of these receptors in inflammatory response. The results of the study indicated that TLR4 and CD14m were expressed in all samples, including the healthy gingival tissue. However, the immunopositive cells for these molecules were increased in gingival tissues of patients with periodontal disease when compared to healthy tissues ${ }^{39}$. According to the authors and considering the limitations of the study, the TLR4 and CD14m receptors are expressed in inflamed gingival tissues of patients with periodontal disease, which implies the potential involvement of these molecules in inflammatory response to periodontal pathogens ${ }^{39}$.

Although there are no studies assessing the levels of expression and the specific molecular mechanisms of the main receptors (CD14 and TLR4) responsible for the recognition of LPS in the apical and periapical tissues of teeth with necrotic pulp and chronic periapical lesion, it is possible to infer, in the light of current knowledge, that these molecules play an important role in the recognition and signaling of LPS. It is logical to infer that CD14 and TLR4 participate in the triggering of the immunoinflammatory reaction in this region, which is responsible for initiation, progression, and maintenance of periapical lesion and also leads to inflammation and bone reabsorption.

\section{FINAL CONSIDERATIONS}

For these reasons, it can be concluded that the identification and characterization of the molecules involved in the triggering of immunoinflammatory events in the host in response to endotoxin (LPS), as well as the molecular mechanisms responsible for these responses, may be seen as potential routes for future studies. Such studies should investigate the modulation of the response of the host for the control and adjuvant treatment for pathologies observed in clinical dentistry. These studies should include patients with periodontal disease and chronic periapical lesions both conditions whose etiopathogenesis is directly involved with bacterial LPS. In addition, these developments can contribute to the prevention of septic shock caused by this main component of the cell wall of Gram-negative bacteria. Currently, in accordance with the specific literature, CD14 and TLR4 play primordial functions and deserve emphasis in future therapeutic approaches.

\section{Collaborators}

MP LUCISANO, RAB DA SILVA and ROSSI were responsible for bibliographic survey through the selection of articles in different databases and for writing the article. LAB SILVA and P NELSON-SON participated in the writing of the article and subsequent corrections of the same. 


\section{REFERENCES}

1. Leonardo MR, Silva $L A B$, Leonardo RT. Tratamento de canal radicular em sessão única: crença vs. ciência. In: Feller $C$, Gorab R. Atualização na clínica odontológica. São Paulo: Artes Médicas; 2000. P. 29-57.

2. Ferrari PHP, Bombana AC. A Infecção endodôntica e sua resolução. São Paulo: Editora Santos; 2010.

3. Mohammadi Z. Endotoxin in endodontic infections: a review. J Calif Dent Assoc. 2011;39(3):153-61.

4. Seltzer S, Farber PA. Microbiologic factors in endodontology. Oral Surg. 1994;78(5):634-45. doi: 10.1016/0030-4220(94)90178-3

5. Rocha $C T$, Rossi MA, Leonardo MR, Rocha LB, Nelson-Filho $P$, Silva LA. Biofilm on the apical region of roots in primary teeth with vital and necrotic pulps with or without radiographically evident apical pathosis. Int Endod J. 2008;41(8):664-9. doi: 10.1111/j.1365-2591.2008.01411.x

6. Martinho FC, Chiesa WM, Zaia AA, Ferraz CC, Almeida JF, SouzaFilho FJ, et al. Comparison of endotoxin levels in previous studies on primary endodontic infections. J Endod. 2011;37(2):163-7. doi: 10.1016/j.joen.2010.11.020

7. Gomes BP, Endo MS, Martinho FC. Comparison of endotoxin levels found in primary and secondary endodontic infections. J Endod. 2012;38(8):1082-6. doi: 10.1016/j.joen.2012.04.021

8. Silva LA, da Silva RA, Branco LG, Navarro VP, Nelson-Filho P. Quantitative radiographic evaluation of periapical bone resorption in dog's teeth contaminated with bacterial endotoxin (LPS) associated or not with calcium hydroxide. Braz Dent J. 2008;19(4):296-300. doi: 10.1590/\$0103-64402008000400002

9. Oliveira LD, Carvalho CA, Carvalho AS, Alves JS, Valera MC, Jorge AO. Efficacy of endodontic treatment for endotoxin reduction in primarily infected root canals and evaluation of cytotoxic effects. J Endod. 2012;38(8):1053-7. doi: 10.1016/j.joen.2012.04.015

10. da Silva RA, Ferreira PD, De Rossi A, Nelson-Filho P, Silva LA. Toll-like receptor 2 knockout mice showed increased periapical lesion size and osteoclast number. J Endod. 2012;38(6):803-13. doi: 10.1016/j.joen.2012.03.017

11. Miyake K, Nagai Y, Akashi S, Nagafuku M, Ogata M, Kosugi A. Essential role of MD-2 in B-cell responses to lipopolysaccharide and Toll-like receptor 4 distribution. J Endotoxin Res. 2002;8(6):449-52. doi: 10.1177/09680519020080061401

12. Salomao R, Brunialti MK, Rapozo MM, Baggio-Zappia GL, Galanos C, Freudenberg M. Bacterial sensing, cell signaling, and modulation of the immune response during sepsis. Shock. 2012;38(3):227-42. doi: 10.1097/SHK.0b013e318262c4b0

13. Miyake K. Endotoxin recognition molecules, Toll-like receptor 4-MD-2. Seminars in Immunology. 2004;16(1):11-6.

14. Tobias P, Ulevitch RJ. Lipopolysaccharide-binding protein and CD14 in the lipopolysaccharide-dependent activation of cells. Chest. 1994;105:48S-50S

15. Dobrovolskaia MA, Vogel SN. Toll receptors, CD14, and macrophage activation and deactivation by LPS. Microbes Infect. 2002;4(9):903-14. doi: 10.1016/S1286-4579(02)01613-1
16. Leonardo MR, Silva RAB, Assed S, Nelson-Filho P. Importance of bacterial endotoxin (LPS) in Endodontics. J Appl Oral Sci. 2004;12(2):93-8. doi: 10.1590/S1678-77572004000200002

17. Paula-Silva FW, da Silva LA, Kapila YL. Matriz metalloproteinase expression in teeth with periapical periodontitis is differentially modulated by the modality of root canal treatment. J Endod. 2010;36(2):231-7. doi: 10.1016/j.joen.2009.10.030

18. Sundqvist G. Ecology of the root canal flora. J Endod 1992;18(9):427-30. doi: 10.1016/S0099-2399(06)80842-3

19. Hosoya S, Matsushima K. Stimulation of interleukin-1 beta production of human dental pulp cells by porphyromonas endodontalis lipopolysaccharide. J Endod. 1997;23(1):39-42. doi: 10.1016/S0099-2399(97)80205-1

20. Rietschel ET, Brade H. Bacterial endotoxins. Sci Am. 1992;267:26-33.

21. Könönen E, Kanervo A, Takala A, Asikainen S, JousimiesSomer $H$. Establishment of oral anaerobes during first year of life. J Dent Res. 1999;78(10):1634-9. doi: $10.1177 / 00220345990780100801$

22. Leonardo MR, Leonardo RT, Nelson-Filho P, Ferrari PHP. A endotoxina e sua importância na infecção endodôntica. Em: Ferrari PHP, Bombana AC. A Infecção endodôntica e sua resolução. São Paulo: Editora Santos; 2010. P. 47-61.

23. Raetz $\mathrm{CRH}$. Bacterial endotoxins: extraordinary lipids that activate eucaryotic signal transduction. J Bacteriol. 1993;175(18):5745-53.

24. Safavi KE, Nichols. FC. Alteration of biological properties of bacterial lipopolysaccharide by calcium hydroxide treatment. J Endod. 1994;20(3):127-9. doi: 10.1016/S00992399(06)80057-9

25. Dixon DR, Darveau RP. Lipopolysaccharide heterogeneity: innate host responses to bacterial modification of lipid A structure. J Dent Res. 2005;84(7):584-95. doi: 10.1177/154405910508400702

26. Hetherington CJ, Kingsley PD, Crocicchio F, Zhang P, Rabin MS, Palis J, et al. Characterization of human endotoxin lipopolysaccharide receptor cd14 expression in transgenic mice. J Immunol. 1999;162(1):503-9.

27. Anas A, van der Pol T, de Vos AF. Role of CD14 in lung inflammation and infection. Critical Care. 2010;14:209.

28. Orstavik D, Ford TP. Apical periodontitis: microbial infection and host responses. In: Orstavik D, Ford TP. Essential endodontology. Oxford: Blackwell; 2008.

29. Consolaro A. Inflamação e reparo. Maringá: Dental Press; 2009

30. Fujihara M, Muroi M, Tanamoto $K$, Susuki $T$, Azuma $H$, Ikeda $\mathrm{H}$. Molecular mechanisms of macrophage activation and deactivation by lipopolysaccharide: roles of the receptor complex. Pharmacol Ter. 2003;100(2):171-94. doi: 10.1016/j. pharmthera.2003.08.003

31. Nelson-Filho $P$, Leonardo $M R$, Silva $L A B$, Assed $S$. Radiographic evaluation of the effect of endotoxin (LPS) plus calcium hydroxide on apical and periapical tissues of dogs. J Endod. 2002;28(10):694-6.

32. Landmann R, Müller B, Zimmerli W. CD14, new aspects of ligand and signal diversity. Microbes Infect. 2000;2(3):295-304. doi: 10.1016/S1286-4579(00)00298-7 
33. Triantafilou K, Triantafilou M, Dedrick RL. A CD14-independent LPS receptor cluster. Nat Immunol. 2001;2(4):338-45. doi:10.1038/86342

34. Triantafilou M, Triantafilou K. Lipopolysaccharide recognition: CD14, TLRs and the LPS-activation cluster. Trends Immunol. 2002;23(6):301-4. doi: 10.1016/S1471-4906(02)02233-0

35. Haziot A, Ferrero E, Köntgen F, Hijiya N, Yamamoto S, Silver J, et al. Resistance to endotoxin shock and reduced dissemination of gram-negative bacteria in CD14-deficient mice. Immunity. 1996;4(1):407-14. doi: 10.1016/\$1074-7613(00)80254-X

36. Moreno C, Merino J, Ramirez N, Echeverria A, Pastor F, SanchezIbarrola A. Lipopolysaccharide needs soluble CD14 to interact with TLR4 in human monocytes depleted of membrane CD14. Microbes Infect. 2004;6(11):990-5. doi: 10.1016/j.micinf.2004.05.010

37. Wright SD, Ramos RA, Tobias PS, Ulevitch RJ, Mathison JC. CD14, a receptor for complexes of lipopolysaccharide (LPS) and LPS binding protein. Science. 1990;249(4975):1431-3. doi:10.1126/science. 1698311

38. Underhill DM, Ozinsky A. Toll-like receptors: key mediators of microbe detection. Curr Opin Immunol. 2002;14(1):103-10. doi: 10.1016/S0952-7915(01)00304-1

39. Becerik S, Ozsan N, Gürkan A, Oztürk VÖ, Atilla G, Emingil G. Toll like receptor 4 and membrane-bound CD14 expressions in gingivitis, periodontitis and CSA-induced gingival overgrowth. Arch Oral Biol. 2011;56(5):456-65. doi: 10.1016/j. archoralbio.2010.11.008

40. Hirao K, Yumoto H, Takahashi K, Mukai K, Nakanishi T, Matsuo T. Roles of TLR2, TLR4, NOD2, and NOD1 in pulp fibroblasts. J Dent Res. 2009;88(8):762-7. doi: 10.1177/0022034509341779

41. Jiang Q, Akashi S, Miyake K, Petty HR. Lipopolysaccharide induces physical proximity between CD14 and toll-like receptor 4 (TLR4) prior to nuclear translocation of NF-kappa B. J Immunol. 2000;165(7):3541-4. doi: 10.4049/jimmunol.165.7.3541
42. Hoshino K, Takeuchi O, Kawai T, Sanjo H, Ogawa T, Taekda Y, et al. Cutting edge: Toll-like receptor 4 (TLR4)-deficient mice are hyporesponsive to lipopolysaccharide: evidence for TLR4 as the Lps gene product. J Immunol. 1999;162(7):3749-52.

43. Kawai T, Adachi O, Ogawa T, Takeda K, Akira S. Unresponsiveness of MyD88-deficient mice to endotoxin. Immunity. 1999;11(1):11522. doi: 10.1016/\$1074-7613(00)80086-2

44. Shimazu R, Akashi S, Ogata H, Nagai Y, Fukudome K, Miyake $\mathrm{K}$, et al. MD-2, a molecule that confers lipopolysaccharide responsiveness on Toll-like receptor 4. J Exp Med. 1999;189(11):1777-82. doi: 10.1084/jem.189.11.1777

45. Nagai $Y$, Akashi S, Nagafuku M, Ogata M, Iwakura $Y$, Akira S, et al. Essential role of MD-2 in LPS responsiveness and TLR4 distribution. Nat Immunol. 2002;3(7):667-72. doi:10.1038/ni809

46. Akashi S, Saitoh S, Wakabayashi Y, Kikuchi T, Takamura N, Nagai $Y$, et al. Lipopolysaccharide interaction with cell surface Toll-like receptor 4-MD-2: higher affinity than that with MD-2 or CD14. J Exp Med. 2003;198(7):1035-42. doi: 10.1084/jem.20031076

47. Zarember KA, Godowski PJ. Tissue expression of human Toll-like receptors and differential regulation of Toll-like receptor mRNAs in leukocytes in response to microbes, their products, and cytokines. J Immunol. 2002;168(2):554-61. doi: 10.4049/jimmunol.168.2.554

48. Schromm AB, Brandenburg K, Loppnow H, Moran AP, Koch MH, Rietschel ET, et al. Biological activities of lipopolysaccharides are determined by the shape of their lipid A portion. Eur J Biochem. 2000;267(7):2008-13. doi: 10.1046/j.1432-1327.2000.01204.x

Received on:24/4/2012

Final version resubmitted on: 30/10/2012

Approved on: 6/12/2012 